\title{
Water-cooling system of the W7-X plasma facing components
}

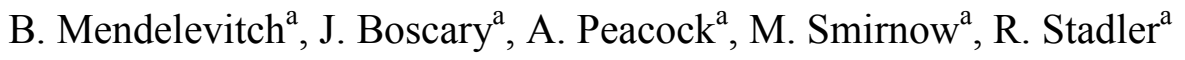 \\ ${ }^{a}$ Max Planck Institute for Plasma Physics, Garching, Germany
}

\begin{abstract}
The water-cooling system of the plasma facing components of the Wendelstein 7-X stellarator was originally conceived for long pulse plasma operation of up to 30 minute duration based on an input plasma power of $10 \mathrm{MW}$. The cooling circuits have been adapted to the intermediate machine operation phases introduced prior to the completion of the full long pulse capability: a first phase with a plasma operation duration $<1 \mathrm{~s}$ and $2 \mathrm{MW}$ input power, a second phase with a plasma duration of 5-10 s. and up to $8 \mathrm{MW}$ input power. In the first operation phase, ten cooling circuits will be water-cooled, and in the second phase, 36 cooling circuits. The circuits which have not been completed are vacuum sealed inside the plasma vessel. During these phases, some of the first wall heat shields will be filled with air and the first wall panels with Neon gas. For the full long pulse operation with all water-cooled in-vessel components, a total of about 430 cooling circuits will need to be put into service.
\end{abstract}

Keywords: Stellarator, Wendelstein 7-X, Plasma Facing Component, Water-cooling

\section{Introduction}

The stellarator Wendelstein 7-X (W7-X) is scheduled to start in 2015. This experimental machine is designed to operate stationary plasma over a pulse length of up to 30 minutes with a $10 \mathrm{MW} \mathrm{cw}$ (continuous wave) input power and peak power with additional combined heating systems of up to $24 \mathrm{MW}$ for $10 \mathrm{~s}$ [1]. A successful long pulse plasma operation requires a reliable and performing water-cooling system [2]. Over the last few years, the planning of the project has been revised and two main intermediate machine operation phases with a simplified configuration have been introduced prior to the completion of the full long pulse capability [3].

In the first operation phase (OP1.1) the plasma duration is $<1 \mathrm{~s}$ with up to $2 \mathrm{MW}$ input power. A temporary inertially cooled limiter made of graphite tiles is installed for the first plasma. In the second operation phase (OP1.2) the plasma duration increased up to 5-10 $\mathrm{s}$ with up to $8 \mathrm{MW}$ input power. A test divertor unit (TDU) [4] which is an inertially cooled divertor made of graphite tiles is installed. The full long pulse operation of the machine is the operation phase 2 (OP2). In OP2 the TDU is replaced by an actively water cooled divertor made of target elements [5].

The water cooling system of the plasma facing components has been originally conceived for OP2. After a description of the organization of the cooling system inside the plasma vessel and of the present status of the mounting operation, the adaptation of the cooling system to the intermediate operational phases OP1.1 and OP1.2 is described.

\section{Organization of the cooling system}

The reference design of the cooling system is that for OP2. The surface of the in-vessel components which face the plasma is approximately $265 \mathrm{~m}^{2}$. The cooling circuits cross the cryostat and the plasma vessel wall through ad hoc flanged penetrations called "plug-ins" installed in these ports [6]. The plug-ins provide for the vacuum boundary between the plasma chamber and the torus hall atmosphere. The position of these plug-ins is shown in Fig. 1 for one module of the plasma vessel, and the machine has a five-fold symmetry. Each module is made of two half-modules, which have an $180^{\circ}$ rotation symmetry. The number and positions of the plug-ins were defined at a very early stage of the W7-X design. The positions were chosen to be as close as possible to the components to be cooled.

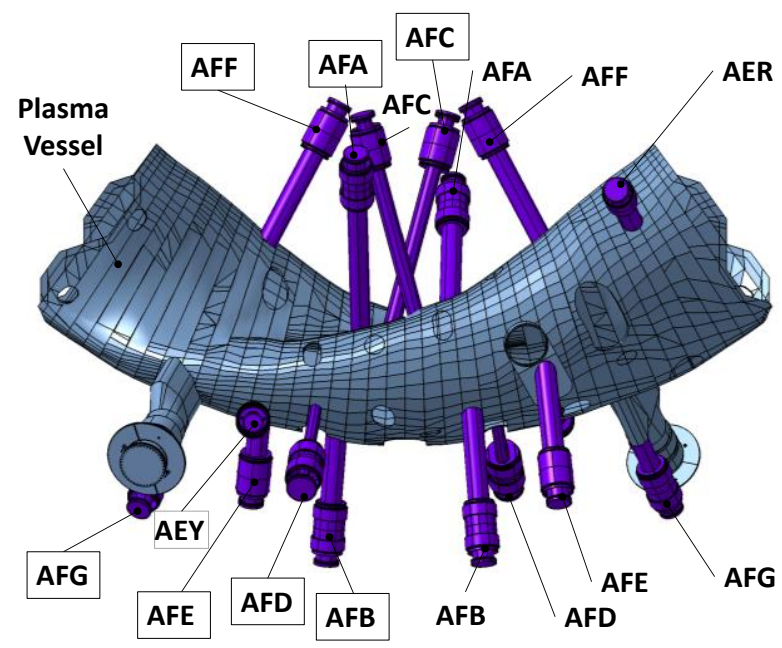

Fig. 1. Location of the plug-ins in one plasma vessel module. The same plug-ins are installed in the two half-modules.

80 of the 244 ports of W7-X (about 1/3) are dedicated to the cooling of the plasma facing components. Due to the plasma vessel symmetry, the set of 8 identical plug-ins AFA-AFG + AER is reproduced 10 times. 30 of them, namely AFE, AFG and AER ports, also include diagnostic cabling. The number of cooling pipes per plug-in varies from 6 to 11 ; the inner diameter of the cooling pipes ranges from 10 to $34 \mathrm{~mm}$. The allocation of the plug-ins to the plasma facing components installed in OP2 is detailed in Table 1. A detailed description of the design, technology and 
characteristics of the different plasma facing components listed in this table can be found in $[7,8]$.

The different loading conditions for the components result in different velocity and operating pressure in plasma operation: $10 \mathrm{~m} / \mathrm{s}$ and $2.8 \mathrm{MPa}$ for the divertor targets, $6 \mathrm{~m} / \mathrm{s}$ and $2.5 \mathrm{MPa}$ for the baffles, divertor closure and heat shields, $2 \mathrm{~m} / \mathrm{s}$ and $2.5 \mathrm{MPa}$ for the panels. The static pressure is $1 \mathrm{MPa}$ and the maximum allowed temperature increase is $50 \mathrm{~K}$. The inlet temperature is $10-30^{\circ} \mathrm{C}$. The different materials in contact with water are stainless steel $(316 \mathrm{~L})$ for the cooling pipes, $\mathrm{CuCrZr}$ of the divertor target heat sinks and Nickel used as transition between $\mathrm{CuCrZr}$ and stainless steel. The selected water parameters for this configuration are: demineralized water, $\mathrm{PH}$ of 6.5 to 8 , conductivity of 2 to $5 \mu \mathrm{S} / \mathrm{cm}$, and allowed particle size $\leq$ $200 \mu \mathrm{m}$.

Table 1. Cooling configuration of OP2.

\begin{tabular}{|c|c|c|}
\hline Components & $\begin{array}{c}\text { Number of } \\
\text { cooling circuits }\end{array}$ & Ports \\
\hline \multicolumn{3}{|l|}{ Divertor } \\
\hline Divertor targets & 130 & $\begin{array}{l}\text { AFB, AFC, AFD, AFE, AFF, } \\
\text { AFG }\end{array}$ \\
\hline Baffles & 70 & $\begin{array}{l}\text { AFA, AFB ,AFD, AFE, AFF, } \\
\text { AFG }\end{array}$ \\
\hline Divertor closures & 20 & $\mathrm{AFE}, \mathrm{AFF}$ \\
\hline Pumping gap panels & 10 & AFA \\
\hline Baffles for cryo-pump & 10 & AFA \\
\hline \multicolumn{3}{|l|}{ First wall } \\
\hline Panels & 40 & AFB, AFE, AFG, AER \\
\hline Heat shields & 46 & AFA, AFC, AFF, AFG, AER \\
\hline Port liners & 102 & Diagnostic ports \\
\hline \multicolumn{3}{|l|}{ Heating port liners } \\
\hline NBI & 4 & AEK \\
\hline Diagnostic NBI & 2 & AET \\
\hline
\end{tabular}

Special solutions have been developed for other types of in-vessel components. The 10 control coils have a special plug-in in the $10 \mathrm{AEY}$ ports (Fig. 1) which includes the water and electrical supplies at the same time. Heating systems such as the Electron Cyclotron Resonance Heating (ECRH), Neutral Beam Injection (NBI) and Diagnostic NBI shield their launching port with water cooled liners. Many ports are used for a large variety of diagnostics; the port walls will be shielded with water-cooled port liners integrated in the diagnostic cooling system for full long pulse operation [9]. At the present stage of the conceptual design, it has been calculated that 102 port liners are required. The plasma vessel is also water-cooled with an independent cooling loop. The complete configuration corresponding to OP2 is the basis for the assembly procedure for start of operation.

\section{Cooling circuit design and assembly}

The approach selected for the assembly of the invessel components was to install as many as possible inside the plasma vessel prior to operation. This sequence also considered possible accessibility issues between the successive operation phases. Cooling circuits have been installed even if it the associated component is not installed as access will be more complicated later on. Simply stated, a cooling circuit consists of the cooling circuit of the plasma facing component itself, the connections inside the plasma vessel to the corresponding plug-in, and the pipes in the plug-in. The majority of the in-vessel components are water-cooled in parallel. The balance between the different branches has been calculated to guarantee the required velocity for the heat transfer with, for a very few circuits, the introduction of restrictions in some of the branches [10]. Therefore, many cooling circuits have a manifold to distribute the water between the different components.

The first wall components are long-term components shielding the plasma vessel and their installation is independent from the mode of operation of the machine. The design of some first wall components has been locally adapted due to special boundary conditions, for example, facing the NBI heating system, or for housing some diagnostics such as the diamagnetic loops. The cooling pipes, which form a 3D network of about 4.5 $\mathrm{km}$, are placed under the first wall components. The cooling structures of the first wall components with their cooling pipes as well as all plug-ins have been installed for the start of operation. Fig. 2 shows a picture of the running mounting activities of the components inside the plasma vessel at the bean-shaped cross section. This figure shows the arrangement of the $\mathrm{CuCrZr}$ cooling structures of the heat shields. The graphite tiles to be clamped onto them will not be mounted for the start of operation.

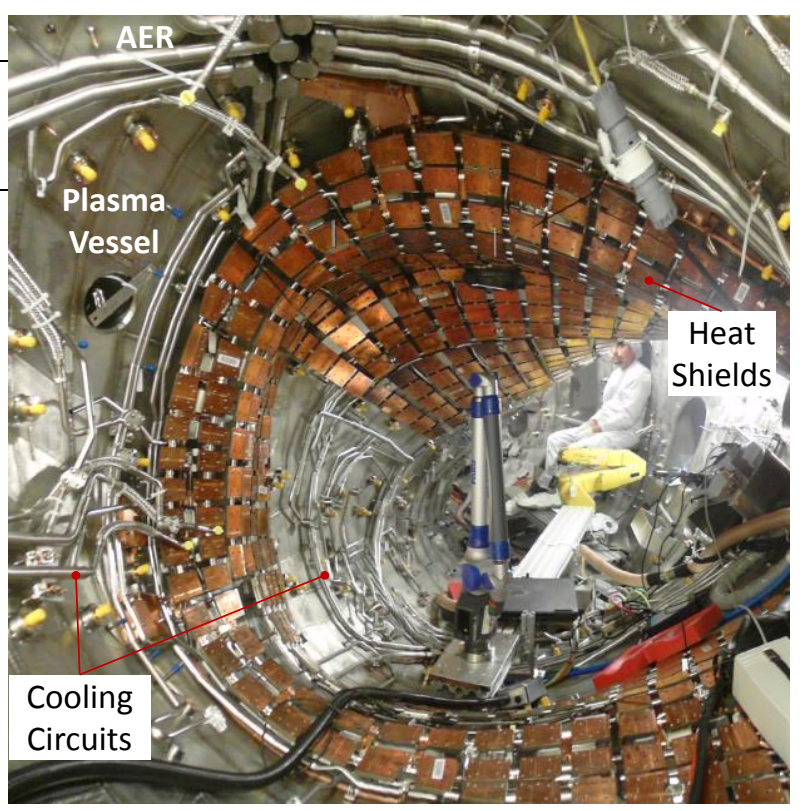

Fig. 2. Cooling circuits and heat shield cooling structure in the near plug-in AER.

On the left of Fig.2, the cooling circuits for the panels are still visible prior to the panel installation. This picture illustrates the difficulties of the mounting operation due to the restricted available space. Nevertheless, the cooling circuits have been installed with a sufficient accuracy of $<5 \mathrm{~mm}$. Most of the cooling circuits have been connected to their relevant plug-ins. Fig. 3 shows the cooling circuits connected via 
T-pieces to the AER plug-in in the plasma vessel module 11. The manifolds distribute the water to the components arranged in parallel. This figure illustrates the difficulty in the optimization of the cooling circuits. The position of the cooling circuits takes into account diagnostic requirements, with as large as possible local pipe diameters to reduce the local velocity and the resulting pressure drop. The average velocity in the piping is $<4 \mathrm{~m} / \mathrm{s}$ to, in addition, avoid possible vibrations.

For the divertor area the corresponding plug-ins have been installed, but the cooling circuits and the connections to the plug-ins will come later.

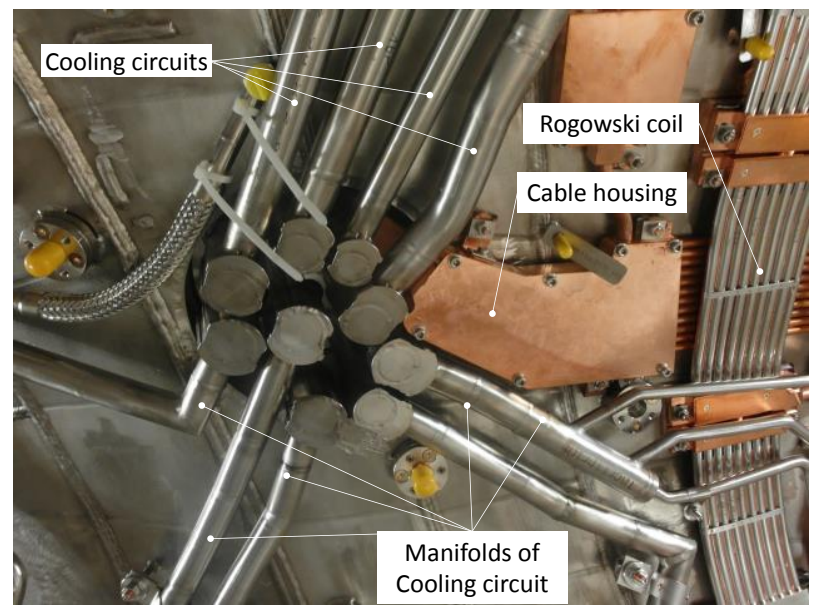

Fig. 3. Cooling circuits connected to plug-in AER11.

A distinction is made between the installation of the components with their cooling circuits and their operation. For first wall components, the difference between the operation phases lies in the feeding conditions. For the divertor areas, this difference lies in both installation and cooling. Next chapters summarize the evolution of the cooling circuits according to the successive operation phases.

\section{Modes of operation}

\subsection{OP 1.1}

For the start of operation, two basic configurations exist. The first configuration is a continuous cooling circuit inside the plasma vessel: the plasma facing component has been installed and connected to the plugin at the inlet and outlet. The second configuration is an interruption of the cooling circuit inside the plasma vessel. In this latter case, seals have to be installed to guarantee vacuum conditions in the plasma vessel. An example is given in Fig. 4 with the AFF plug-in in the plasma vessel module 51 . This picture has been taken at an intermediate stage of assembly. This plug-in has four pipes for the divertor targets, four pipes for the baffles and one pipe for heat shields of the first wall. In OP1.1 the divertor targets have not been installed; the relevant pipes are sealed by immersion sleeves at the plasma vessel side. The baffles have also not been installed and the corresponding pipes are sealed with blind flanges. The remaining heat shield cooling circuits will be completed for OP1.1.

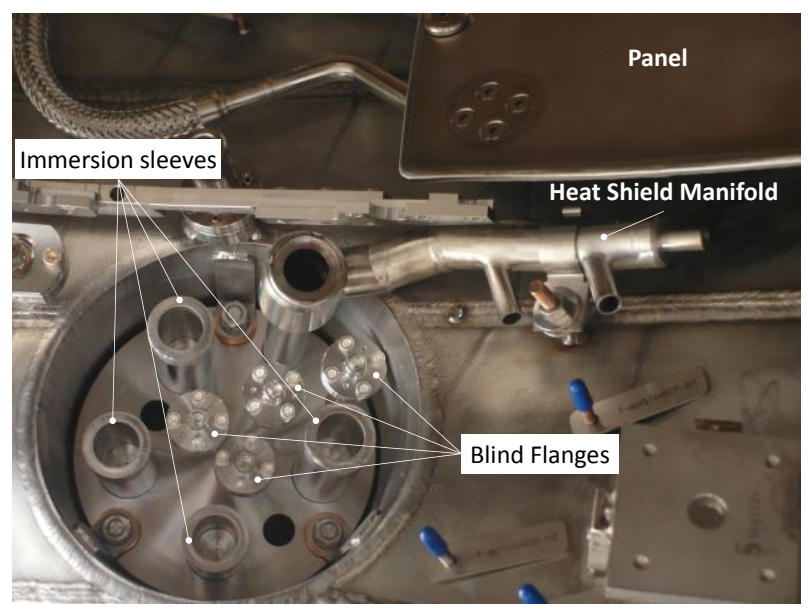

Fig. 4. Plug-in AFF51 in OP1.1

About 400 immersion sleeves and 130 blind flanges are to be installed in OP1.1.

The OP1.1 plasma operation for $1 \mathrm{~s}$ at reduced input power does not require water-cooling of plasma facing components. One cooling circuit of the first wall panel includes the housing of the glow discharge electrode placed in each of the ten half-modules of the machine. This component needs to be water-cooled to operate between pulses. The panels which belong to this circuit will be consequently water-cooled, even if it is not required. The resulting total flow rate for the plasma facing components is $58 \mathrm{~m}^{3} / \mathrm{h}$. Only 10 cooling circuits will be fed with water. Excluding port liners, this corresponds to $3 \%$ of the cooling circuits. The ten control coils will be also operated at a reduced water velocity with a total flow rate of $3.15 \mathrm{~m}^{3} / \mathrm{h}$. The heat shields of the first wall are all connected to the plug-ins and the pipes in the plug-ins are connected to the torus hall atmosphere. These pipes will remain open and will contain air. Due to their technology, the first wall panels [11] need to be filled with a gas such as Neon to maintain their mechanical stability during operation. The components will be filled with gas at the flanges of the plug-ins outside the machine and sealed. In summary, there are three configurations of cooling circuits in OP1.1: air filled, gas filled and water-cooled.

\subsection{OP 1.2}

The OP1.2 plasma operations require obviously much more water-cooling capabilities to protect the plasma vessel and to shield some diagnostics. Most of the heat shields and panels in modules 1 and 5, where the ECRH launchers are located, need to be water-cooled. The AEK port protection of the NBI system in halfmodules 20 and 21 and the AET port protection of the diagnostic NBI system in half-module 41 are also to be water-cooled. The NBI operation requires in addition the water cooling of the components facing the beams, namely some heat shields and also some baffles of the divertor area. Some heat shields are also used as diagnostic housings: the Soft-X multi camera system in six half-modules and the diamagnetic loop in two halfmodules. The ten control coils remain water-cooled with the same parameter as in OP1.1. Table 2 summarizes the OP1.2 cooling configuration and lists the number of 
cooling circuits which are air filled, gas filled or watercooled.

Table 2. Cooling configuration of OP1.2.

\begin{tabular}{lccc}
\hline Components & \multicolumn{3}{c}{ Number of cooling circuits } \\
& Air & Gas & Water \\
\hline Divertor & - & - & - \\
Divertor targets & - & - & 2 \\
Baffles & - & - & - \\
Divertor closures & - & 10 & - \\
Pumping gap panels & - & - & - \\
Baffles for cryo-pump & & & \\
& - & 26 & 14 \\
\hline First wall & 36 & - & 14 \\
Panels & - & - & - \\
Heat shields & & & \\
Port liners & & & 4 \\
& - & - & 2 \\
\hline Heating port liners & - & 36 & 36 \\
NBI & & & \\
Diagnostic NBI & 36 & & \\
\hline Total & & & \\
\hline
\end{tabular}

This table does not include additional cooling requirements for independent diagnostics and also the control coils. Excluding the port liners, the number of water-cooled circuits corresponds to $11 \%$ of the cooling circuits. The total calculated flow rate for the plasma facing components is $200 \mathrm{~m}^{3} / \mathrm{h}$, which is 2.4 times more than in OP1.1.

The different modes of operation of the cooling circuits are: stand-by or maintenance with possibly opened plasma vessel, plasma operation and baking. Baking will be performed at $150^{\circ} \mathrm{C}$.

\subsection{OP 2}

This configuration has been detailed in the previous paragraphs. In OP2, with the installation of the HHF divertor targets and the full long pulse operation, all invessel components have to be actively water-cooled. Compared to OP1.2, the number of cooling circuits is multiplied by about 10 . With a total calculated flow rate of $2400 \mathrm{~m}^{3} / \mathrm{h}$, the water quantity is multiplied by 12 .

An additional mode of operation, namely the hot liner operation, is available in OP2. With an inlet temperature of $120^{\circ} \mathrm{C}$ of the first wall components, a fast balance between adsorbed and desorbed particles at the wall may be reached.

\section{Conclusion}

The water-cooling system of the plasma facing components designed for full long pulse operation OP2 has been adapted to the intermediate machine operation phases OP1.1 and OP1.2 with a simplified configuration. First wall components, namely the heat shields and panels with their cooling circuits as well as the plug-ins to feed them, have been installed from the start of operation. In order to study plasmas, an inertially cooled limiter for $1 \mathrm{~s}$, an inertially divertor for 5-10 $\mathrm{s}$ and an actively cooled divertor for 30 minutes will be successively installed. The water cooling system will be put in operation accordingly. The adaptation of the OP2 cooling circuits to the intermediate phases was made possible by the development of different technological solutions to seal the pipes inside the plasma vessel.

OP 1.2 offers a good possibility to operate the water cooling system with a reduced number of actively cooled components to gain experience for the transition to OP2. This phase is a big step in putting the cooling circuits into service. The cooling circuits are a spider's web of about $4.5 \mathrm{~km}$ of piping and manifolds placed under the plasma facing components. The efforts invested in the design, assembly and quality control will allow W7-X to get a reliable water cooling system to finally demonstrate the natural ability of the stellarator geometry for stationary plasma operation.

\section{Acknowledgments}

This project has received funding from the EURATOM research and training programme 20142018.

\section{References}

[1] M. Gasparotto et al., Wendelstein 7-X - Status of the project and commissioning planning, Fus. Eng. and Des. 89 (2014) 2121-2127.

[2] M. Chantant et al., Computation of Tore Supra cooling system limits, Fus. Eng. and Des. 87 (2012) 1171-1176.

[3] H. S. Bosch et al., Transition from construction to operation phase of the Wendelstein 7-X stellarator, IEEE Trans. on Plasma Sci. 42 (3) (2014) 432-438.

[4] A. Peacock et al., Progress in the design and development of a test divertor (TDU) for the start of W7-X operation, Fus. Eng. and Des. 84 (2009) 1475-1478.

[5] J. Boscary et al., Summary of research and development activities for the production of the divertor target elements of Wendelstein 7-X, IEEE Trans. on Plasma Sci. 42 (3) (2014) 533-538.

[6] B. Mendelevitch et al., Design Analysis and Manufacturing of the cooling lines of the in vessel components of Wendelstein 7-X, Fus. Eng. and Des. 86 (2011) 1669-1672.

[7] R. Stadler et al., The in-vessel components of the experiment Wendelstein 7-X, Fus. Eng. and Des. 84 (2009) 305-308.

[8] J. Boscary et al, Design and technological solutions for the plasma facing components of W7-X, Fus. Eng. and Des. 86 (2011) 572-575.

[9] R. Stadler et al., Conceptual design of the W7-X port liners, this conference.

[10] M. Smirnow et al., Hydraulic analysis of the Wendelstein 7-X cooling loops, , Fus. Eng. and Des. 88 (2013) 1764 1767.

[11] A. Peacock et al., The procurement and testing of the stainless steel in-vessel panels of the Wendelstein 7-X stellarator, Fus. Eng. and Des. 86 (2011) 1706-1709. 